\title{
Language Practice and the Dilemma of a National Language Policy in Ghana: The Past, Present and Future
}

\author{
Aboagye Da-Costa, Caroline \\ Adade-Yeboah, Asuamah \\ Christian Service University College \\ P. O. Box 3110 \\ Kumasi, Ghana
}

\begin{abstract}
In addressing language issues within the public domain, linguistic hegemonies and power relations are maintained by the roles of law, education and media. In Ghana, the Official Language Policy, Schools' Language Policy and the languages promoted in the media are treated independently. This study attributes the lack of concord to the nonexistence of a law or a National Language Policy which gives a language direction. Though the effect of the nonexistence of a law may seem unfelt, its negative impact is weaving its way in the other areas of media and education.By interviewing and observing media professionals in their work contexts as well as content analyses of the Broadcasting Act and the Guidelines for Local Language Broadcasting, the current language situation in Ghana is discussed, driving home the idea that without a National Language Policy with an indigenous Ghanaian pride, efforts at developing indigenous languages will continue to dwindle into extinction.
\end{abstract}

Keywords: education; English Language; extinction; Ghana; indigenous language; law;media; national language policy

\section{Introduction}

In the absence of a National Language Policy to define the position of the English language as well as the seventy-five (75) rich, original and unique spoken indigenous languages ${ }^{1}$ (Blankson, 2005, p.11), language issues in Ghana have been inconsistent. While the English language is projected in some quarters, local languages receive endorsement in others. Projecting the English language as the official language and Schools' language has left a significant percentage of Ghanaians marginalised. Ghana, like many other African countries, has only a minority of the adult population understanding and being proficient in the ex-colonial language of English. In the media, especially those of broadcast, however, indigenous languages are promoted. Discussions with regard to defining official and national languages and ultimately to develop a National Language Policy have been on the drawing table since independence but is yet to see the light of day, essentially because of the various views expressed and the lack of consensus.

Linguistic hegemonies and power relations in the public domain can only be maintained by the role of three pillars: law, education and media (Spitulnik, 1998, p.164-165). In the absence of a National Language Policy (law), various sections of the economy treat language independently and have developed bits and pieces of language policies, with different and isolated language interests, as may be feasible for their activities. Language issues are handled individually, not giving thought to the fact that they need to be synchronised. The English language, viewed as superior to indigenous languages, is projected as the esteemed official language and for use in schools (education) which is the reserve for a few. In the media however, which is considered as an avenue for democracy and so everybody is expected to have access and be informed (Mpofu \& Mutasa, 2014), local languages are promoted, as evidenced in the numerous normative media documents.

With about seventy-five (75) indigenous languages where none is touted as a national language, the lack of a national language policy with Ghanaian pride may be weaving negative impacts into the development of indigenous languages on the quiet since the lack of their wide use curtails efforts in developing them with exhaustive vocabulary. This silent killer of indigenous languages, just like hypertension in humans, may send a lot of indigenous Ghanaian languages into extinction in the next decade or two, if not given the needed attention.

\footnotetext{
${ }^{1}$ It is unclear the number of indigenous languages spoken in Ghana. While Blankson (2005:11) puts the number at seventyfive, Boadi (1971:49) argues the number to be over forty. Spencer (1971:2) puts the number at thirty and Grimes (1984:88) puts the number at sixty. The University of Ghana puts the number at forty-four (Dakubu 1988:10).
} 
When language planning is left in the hands of political governments who have little or no interest, the expected results may be difficult to achieve since successive governments have different ideologies in this regard. This paper discusses the language situation in Ghana on the three pillars of the law, education and the media, projecting that the language situation in Ghana has been inconsistent due to the lack of a National Language Policy to direct the language affairs of the country.

\section{The dilemma of a Law or National Language Policy in Ghana}

Ghana does not have an overarching and focused national language policy or law that gives an all-encompassing direction to the use of indigenous Ghanaian and the English languages in government business, education and the media. Rather, bits and pieces of language policies to regulate various sectors of the economy, as may be deemed fit have been established. The socio-political choice of English as an official language, the determination of the place of local languages, the debate on national languages, as well as National Language Policy in Ghana often swings like a pendulum, appearing at some time, disappearing at another and then re-surfacing again. Dzameshie (1988) attests that the issue of a national language policy in Ghana has been on the drawing board since independence, but to date, a Ghanaian National Language Policy with a Ghanaian pride has not seen the light of day.

The views for inclusion of languages into the National Language Policy at separate parliamentary discussions since 1971 had been split, with one school of thought advocating for maintenance of the English language as national official language on the merit that no Ghanaian language had an indigenous coverage of 50\%. Thus, a "neutral" language that transcends tribal language barriers, which was English language was adopted. Another school of thought held a view to adopt one Ghanaian language and develop it well as the national official language since "an African state needs to throw off its European legacy and adopt an African language and on the conviction that English will never be enough spoken in these (African) countries to constitute an effective medium of national communication" (Dzameshie, 1988, p.21). A third view was held to the effect that one indigenous Ghanaian language should be selected and developed to be used alongside the English language. In that regard, while the English language catered for external or international communication, the indigenous Ghanaian language could be used for national or local communication. On this view, a case was being made for the Akan language since it had the largest indigenous coverage but there were opposing views that Akans would feel superior to the other "minority" languages. There was yet another view which suggested that, a limited number of indigenous languages (possibly four) should be selected to create a national language policy. The final view was a natural selection strategy where all Ghanaian languages were to be allowed to co-exist so that without any government sponsorship or effort, one could emerge to be adopted as a national official language. With the lack of a consensus, the project on developing a National Language Policy seems to have been abandoned, more especially because the English Language seems to be serving our purposes.

\section{Official language use in Ghana}

Globally, the decision to adopt or not to adopt ex-colonial languages as official languages after independence had been dependent on a number of factors. These include the past political history, the bond with the colonial master at the time of independence, the nature of the governance and political system to be adopted, and to some extent the language situation in each country (Moyo, 2002, p.150). Ghana, like many other multilingual and multiethnic countries which were colonised by the British adopted the use of the English Language as official language after independence, thus, English language was used for all official correspondence. While the English language had been maintained to today as the official language and occupies a prestigious position, the fate of indigenous Ghanaian languages has been left on the hook and is not defined. The choice of the English Language for official purposes in Ghana had been argued on the basis that it was politically neutral; it had a global outlook with international and diplomatic discourse; and it was capable of promoting national integration at a political level since it had no ethnical, cultural, political or ideological alliance (Opoku-Amankwah, 2009, p.122; Pennycook 1995, p.37 cited in Iseke-Barnes, 2004; Obeng 1997, p.71; Dua 1993, p.299;). Further to this, it was seen as the only language with specialised and exhaustive vocabulary necessary for secondary discourse, which goes beyond the primary discourse of the everyday private domain (Gough, 1999). No indigenous Ghanaian language had been touted as a national language or developed to equal the English language so it was all about the English language. Thus, the idea of promoting the culture, languages and national solidarity of Ghana had been down-played in the face of the need to be operationally efficient, by adopting an ex-colonial language.

While local languages are not restricted for official businesses and correspondences in Ghana, the practicality is in doubt. Some legislative documents in Ghana recommend the use of indigenous languages for official business, provided that all the parties to the communication understood the language. Article 26(1) of the 1992 Constitution stresses that "Every person is entitled to enjoy, practice, profess, maintain and promote any culture, language, tradition or religion subject to the provisions of this Constitution". 
Additionally, at the local government level, a "District Assembly may conduct its business in English and in a Ghanaian language common to the communities in the District" (Ghana, 2016). Again, the Standing Orders of the Parliament of Ghana (Parliament of Ghana, 2000, p.29-30) allows for debates to be conducted in Ghanaian languages if a member so desired.

However, when at the current parliament (the $7^{\text {th }}$ Parliament of the $4^{\text {th }}$ Republic of Ghana), a member of parliament had difficulty expressing herself in the English Language, she was mocked, not only by her colleague parliamentarians, but the general public as well. This compelled her to be silent in parliament for about a year until the time when she learnt the English language. She made her first speech on the floor of Parliament on $19^{\text {th }}$ December, 2017 (peacefmonline.com, 2017). Where is the place of indigenous languages in the official business of Ghana, if we cannot uphold what the 1992 Constitution and the Standing Orders of Parliament profess?

\section{The fate of indigenous Ghanaian languages in education}

The ripple effect of the lack of a policy document that gives direction on language use in Ghana has been massive in other spheres of national discourse, including the other two pillars of education and the media. Obeng (1997, p.71-72) opines that unlike the German colonial administration that saw the importance of indigenous languages and encouraged their use, the British colonial administration language policy saw a complete imposition of English language on their colonies. Additionally, "the negative attitude of Ghanaians towards their own languages and the prestige which they attached, and still attach, to English language also helped in the consolidation of the position of English in the academic curriculum" (Obeng 1997, p. 72). Before independence in 1957, nine (9) (or better still eleven (11)) out of seventy-five indigenous Ghanaian languages were approved for use in schools - Akan (in its three varieties of Asante Twi, Akuapem Twi and Fante), Dagaare-Wali, Dagbani, Dangme, Ewe, Ga, Gonja, Kasem and Nzema (Opoku-Amankwa, 2009, p.122). While these languages have been studied as a subject at the upper primary to the junior high level, the problem has been at the lower primary level which happens to be the formative years of school going pupils. The Schools' Language Policy has been very dramatic even before independence to the present day.

In education, Owu-Ewie (2006) opines that the Schools' Language Policy in Ghana had been checkered from the colonial era to date, showing massive inconsistencies. The decision on which language to use at the lower primary level, has been an issue left at the mercy of successive political governments and which ideology they wished to project (Opoku-Amankwah, 2009; Owu-Ewie, 2006). From 1925 to date, Ghana has had seven (7) Schools' Language Policies for the lower primary level. From the period spanning 1925 to 1951, local languages were used as the medium of instruction from lower classes one to three. This policy was changed between 1951 and 1956 when local languages were used only at lower class one. Again, the policy was changed between 1957, when Ghana gained independence, and 1966. This time, no local language was used as medium of instruction in schools. Between 1967 and 1969, the policy was again reversed, where local languages were used only at basic class one. Between 1970 and 1974, the policy was to use the local languages for basic classes one to three, and where possible, extend it beyond, up to class six. The era between 1974 and 2002 experienced another policy, which required educators to use the local languages as mediums of instruction for basic classes one to three. Currently, the policy in use, adopted in 2002, requires the use of only English as language of instruction in schools, with one Ghanaian language studied as a compulsory subject. In all these back and forth decision-making, the multiethnic and multilingual situation of Ghana had been cited and the contention had always been the language of instruction at the formative years in school.

It is unclear if any evaluations were performed on the effectiveness or otherwise of the various policies implemented and what impact they had on learners over the years before they were changed. However, Moyo (2002, p.154) demonstrated by his research in the Zambian situation that the current Schools' Language Policy practiced in Ghana resulted in students being poor learners both in the indigenous and the English languages.

At the Senior High School to university levels, Ghanaian languages are studied as subjects depending on the programme enrolled in, while English remains the language of instruction in all other subjects. Not all programmes of study therefore have local languages incorporated as subjects. Even in the case of Ghanaian language study, some aspects like the syntax and phonology are taught in the English language since examination questions in those areas are set in the English language (Obeng, 1997, p.74). When a student decides to attend a technical school, on the other hand, there is no option for the student to study any indigenous language. Do indigenous languages matter in Ghana?

\section{Indigenous Ghanaian languages in the media}

Africa is often called the Tower of Babel because it is endowed with a myriad of languages. The United Nations Educational, Scientific and Cultural Organisation (UNESCO) estimates Africa's languages to be 2,058, constituting about $30 \%$ of the world's languages (Roy-Campbell, 2006, p.9). However, very few of these languages are used in the media, which is dominated by ex-colonial languages. 
Ex-colonial languages used in the media were influenced by colonialism, Christian Evangelical missions and the subsequent adoption of ex-colonial languages as official languages by most African countries (Adedeji, 2015, p.35). English is the dominant language in Ghana essentially because it is the official language and the medium of instruction in schools.

It is promoted widely everywhere except in the media, which are considered as "a crucial tool for information dissemination, public discussion and debate, communication of social thought, as well as a means to challenge and legitimise governments" (Mpofu \& Mutasa, 2014, p.226). Though broadcasting was introduced into the Gold Coast in the English Language, the government of Ghana and all media regulators promote the use of local languages so that even illiterates would be informed about happenings in the country. As at the 2010 Population and Housing Census, a substantial percentage (23.4\%) of the Ghanaian population was illiterate (Ghana Statistical Service, 2012, p.7-8), this notwithstanding, their information needs have been catered for in the broadcast media.

Broadcasting transmission in Ghana was started in the English language in 1935 by the then governor, Sir Arnold Hodson, to mark the silver jubilee of King George V of the British Empire (Alhassan, 2005, p.211-212). Based in Accra, Station Zoy, as it was called, was an extension of Empire Service in London, relaying its programmes to the newly formed radio station in the colony. Even after independence, the choice of English language for official correspondence affected the language of the media. It was dominated by the English language to the extent that by late 2000, four years after the media airwaves were liberalised, not a single FM station was broadcasting in the local language (Blankson 2005:11). All the new FM stations that came into the media scene like Joy FM, Gold FM, Vibe FM, Legon FM and Groove FM broadcast solely in the English language (Blankson, 2005, p.11; Ansu-Kyeremeh, 2002; Obeng, 1997, p.65). A substantive portion of Ghana's population was marginalised because of the language barrier. They could not understand the English language because they were illiterates. Today, the story has changed. Broadcasting, which started in the English language, now has about two-thirds of FM stations nationwide broadcasting in Ghanaian languages, with Ghana Broadcasting Corporation alone broadcasting in more Ghanaian languages than any other (Ansu-Kyeremeh, 2002). A number of TV stations have also joined the local language train. However, as Blankson (2005, p.8-9) reveals, this was not achieved on a silver platter. It took criticisms as well as internal and external pressures for the trend to change through the introduction of stations like Peace FM, which broadcasts solely in the local language. Internal pressure came from the Ghanaian academic community, which organised conferences to debate the role of the press for democracy and media liberalisation (Blankson, 2005, p.9; School of Communication Studies, 1993). External pressures were experienced as a result of the new era of political pluralism and neo-liberal economic policies across sub-Saharan Africa (Blankson, 2005, p.9; Heath, 2001).

In today's Ghanaian local language media, local language radio and television to be precise, all programmes including the news are presented in the local language but it is interesting to note that news scripts are written in the English language and translated on the spot during news time (Aboagye Da-Costa, 2018; Opare-Henaku, 2016; Nyavor, 2010). Newscasters in the various indigenous language broadcast stations find it difficult to write the news scripts in the indigenous languages though that is what the media regulator in Ghana expects and spells out in sub-section 2.3.4 of the Guidelines for Local Language Broadcasting (National Media Commission 2009). The reasons for this practice are varied. Aboagye Da-Costa (2018) opines that part of the reason is attributable to the non-exhaustive vocabulary of indigenous languages. Newscasters therefore do not get substitutive indigenous language words for English language words. In translating information from English to the indigenous languages, the practice has been to paraphrase information or use a lot of local language words to explain ideas which would translate into cumbersome and lengthy scripts. Another reason is that some newscasters were fluent in speaking the local language because it was their mother tongue but were not fluent in writing it. Most local language FM stations employ their newscasters on their oratory ability to speak the local languages with appellations and proverbs (Aboagye Da-Costa, 2018; Opare-Henaku, 2016) rather than their ability to write it. To avoid all these, scripts are written in the English language and translated on the spot during presentation.

The position of language in the Ghanaian media is explicitly spelt out in the various normative media documents from the National Media Policy (2000), the Broadcasting Act (2014), the Broadcasting Standards (2001) to the National Media Commission's Guidelines for Local Language Broadcasting (2009), which is specifically fashioned to guide local language broadcast media. Though these media regulator documents are pieces of information meant for purposes other than language use in Ghana, they all promote the use of local languages in the media, largely because of the media's wide-reaching effect to get the population informed. The presentation of these documents acknowledge the multiethnic, multicultural and multilingual situation of Ghana, as well as the high illiteracy rate and as such project the use of local languages. In a nutshell, all media houses are encouraged to operate in the local languages prevalent in their regions and domains of operation. It is interesting to note that even without strict enforcement, this is being done. 
If radio programming in Ghana should be multi-linguistic in nature to reflect the national outlook of the country and also inform all and sundry irrespective of their literacy status without barrier, why then would the official language policy and the Schools' Language Policy not show a similar reflection?

\section{The way forward}

There are so many ... things eroding language in our communities. In schools they're talking more English. And in business affairs, business terminology is in English; people talk English in meetings and functions. All of these things lead to breakdown of a language community. People begin to use English words in their Mi'kmaq dialect, and switch back and forth. They need to be caught in the switch, which is what we're trying to do in the school - to catch the switch by saying, "let's be conscious of the words we use. If you don't know what a word is in Mi'kmaq, let's ask and find out, and we will use those words, and if we can't think of the word, then we might use the English word or find a new word for it." So, for example, even in things like studying about food, we learn the Mi'kmaq words. There's a Mi'kmaq word for carrots, there's a word for peas, there's a word for corn. Yet only a portion of these Mi'kmaq words are being used in daily dialogue with the children in their homes. So we want to provide them with the proper words. (Interview between Battiste and Martell in 1992 cited by Iseke-Barnes (2004, p.65-66))

The opening statement of this section is an excerpt of an interview between Battiste and Martell in 1992 cited by IsekeBarnes (2004, p.65-66). It connotes the language situation and also summarises how to deal with the language situation in Ghana as regards indigenous languages.

Language planning and policy making of any country often paves a language direction, especially in multicultural and multilingual nations like Ghana. However, if the process is not handled well, language planning brings about divisions that foster inequalities on sociocultural and econo-technical grounds (Fishman, 1994, p.93), leading to divisions among linguistic groups, whereby some are advantaged and others disadvantaged (Spitulnik, 1998). These unequal divisions sometimes further lead to the propagation of unequal divisions of power and resources among social and linguistic groups within the same country, thus, generating anger and in-fighting, as well as inferiority and superiority among linguistic sects. The avoidance of 'unequal power' divisions might be a reason why Ghana has been slow on drawing up a National Language Policy and to accord some indigenous languages the national language status.

It is worth knowing that without deliberate national efforts at developing and promoting indigenous languages, some of them may go extinct with the passing of time. This wake-up call has been hammered earlier by Ghanaian scholars including Obeng (1997, p.63). Countries like Nigeria, Zambia, Kenya and South Africa have made great strides in terms of developing vocabulary for their indigenous languages, with countries like Kenya and South Africa projecting some of them to official language status. This is contrary to most African countries, including Ghana, who still use only ex-colonial languages as the lingua franca. Salawu (2010, p.67-68) corroborates the fact that some African indigenous languages had been given a face lift, whereby they were being adapted to fit into the world of information technology to make computers accessible to the speakers. Kenya, which was far advanced in this hi-tech indigenous language application, has seen great advancement by Microsoft to incorporate Swahili, which is a well-developed indigenous language, into Microsoft Windows, Microsoft Word and other programmes. Other South African, Kenyan and Nigerian languages like Amharic, Zulu, Yoruba, Igbo, Afrikaans and Hausa were also in the pipeline to benefit from same. Additionally, he notes that, the first African indigenous keyboard had been developed for the Yoruba language and voice recognition software was also being developed to convert spoken Yoruba into text. Until indigenous Ghanaian languages are "regarded as cultural capital of the cultural communities" (Mpofu \& Mutasa, 2014, p.227), without which Ghanaians consider themselves as lost or empty, efforts at developing, promoting and projecting them will continue to dwindle.

The issue of political will on issues of indigenous language development cannot be downplayed. In Ghana, like many African countries, where governments have so much power at their disposal, the commitment or otherwise to get policies formulated and implemented effectively have been discussed widely. The approach to language planning in Africa, Bamgbose (2007, p.111) attests “... is characterised by several undesirable features such as avoidance of policymaking, vagueness of formulation, arbitrariness, inconsistency and fluctuation, and declaration of policy without any serious intention of implementation."

A lack of political will is evident in the delayed decision making on matters on language, where sometimes policies were formulated but never implemented. Sometimes policies were drawn up, but without clear implementation modalities or an understanding of whether they would be feasible in the context of application, thus making them difficult to work with. There is a need for a policy direction to be explicitly documented and to be backed by political will and possibly a law to ensure that it works. 
In Ghana, while a law or National Language Policy is not existent and as such the English language is pushed forward as the official language, the Ghana Schools' Language Policy is also pushing the English language. On the contrary, the National Media Policy and all other normative media documents are pushing the use of local languages in the Ghanaian media. A language policy in the media should not be drawn in isolation from the National Language Policy (Mpofu \& Mutasa, 2014, p.227). There should be an overarching document whose function would be to solely synchronise all other language documents and also spell out the place of indigenous languages and the English language for official communication, in the media and in schools.

The Bureau of Ghana Languages, formerly known as the Vernacular Literature Bureau, whose publications the National Media Commission recommends as reference for local language broadcasting (National Media Commission, 2009, p.10), has since 1951 been working in and publishing literature in only the 11 government-sponsored indigenous languages - Asante Twi, Akuapem Twi, Fante, Dagaare-Wali, Dagbani, Dangme, Ewe, Ga, Gonja, Kasem and Nzema. Among other things, the Bureau's mission is to "provide services in Ghanaian languages to individuals, organizations, institutions and the general public through research into Ghanaian languages, writing, translation of non-local language documents, assessment, editing and publication of documents in Ghanaian languages and to influence government policies on Ghanaian languages" (National Commission on Culture, n.d). With only two offices in Accra and Tamale, governmental, corporate and individual support for language development has not been encouraging so the Bureau has found it difficult to channel efforts in developing other indigenous languages aside the eleven. Their efforts are highly recognised but need to be sustained and, ultimately, maximised to avoid the cycle of language attrition, language suicide, language moribundity and finally language extinction due to the over reliance on global languages like the English language (Obeng, 1997, p. 77-78; Crystal 2003,p.20).

With only 11(15\%) of Ghanaian indigenous languages having written forms (Opoku-Amankwa, 2009, p.122) with essential but non-exhaustive vocabulary (Aboagye Da-Costa, 2018), their use in media and other spheres has been limited. On Ghanaian local language radio, for instance, the non-availability of exhaustive vocabulary has created the avenue to code-switch the local language with English language (Flamenbaum, 2014), when appropriate vocabularies were not found or paraphrasing to explain ideas (Aboagye Da-Costa, 2018). The over-reliance of Ghanaians on the English language does not encourage research into indigenous Ghanaian languages.

The position of Ghana has not been indicative of an urgent move to achieve indigenisation. In a country with about 75 indigenous languages, it may be difficult to accord the national language status on one indigenous language, especially since none of them is indigenous to $50 \%$ or more of the population. The multicultural and multiethnic state of Ghana makes it pertinent to play it safe by choosing a neutral language as national language, however, the Akan language (with all its variants) would not be difficult to adopt in this regard. The language enjoys some amount of prestige even among the other indigenous languages. Aside from the fact that it is indigenous to $47.5 \%$ of the Ghanaian population (Ghana Statistical Service, 2012, p.5), it is spoken nationwide by both indigenes and non-indigenes alike. Obeng (1997, p. 64) accentuates that even before 1997, the Akan language was spoken by $60 \%$ of the Ghanaian population as a second language. Further to this claim, he contends that "Of all the Ghanaian languages, Akan has the largest amount of written texts including creative literature, and is therefore the most widely studied and documented".

Alternatively, a limited number of indigenous languages could be accorded the national language status alongside the English Language as in the case of South Africa ${ }^{2}$ and Kenya. Those privileged indigenous languages would then have to be developed with comprehensive vocabulary. The eleven languages which already have written forms and have been adopted for use in schools could be the point to start with. They could then be planned into a national language policy with a Ghanaian pride. It might be argued that developing and promoting a number of indigenous languages to national language status would be expensive considering the time, effort and money to be channelled into such an activity but determination can achieve it. Moyo (2002, p.154) argues that South Africa channelled personnel and economic resources to develop Afrikaans as a medium of instruction from the basic education level to the tertiary level over a period of more than one hundred years. Germany, France and Kenya also number in the countries that have channelled effort and resources into their indigenous languages. Even the English Language which developed in Europe around the $5^{\text {th }}$ Century and has been adopted as official language took over 1400 years to develop it to its present state, becoming a global language (Crystal, 2003, p.30). From one small island, the English language is now linqua fraca in about 100 countries worldwide.

The story is not that gloomy in the situation of Ghana. The Akan language, for instance, as well as the Ga, Hausa and Ewe languages have seen face-lifts. Google launched Akan, Ewe, Hausa and Ga versions offering native speakers an opportunity on its popular search engine. But in a country with seventy-five languages, whereby only eleven have written forms, the nation needs to step up its game or risk losing its indigenous languages.

${ }^{2}$ South Africa, for instance, has eleven official languages, ten of which are indigenous. 


\section{Conclusion}

The choice of the English language as official language in Ghana has impacted the languages used in all other spheres. With sustained efforts at projecting the English language above indigenous Ghanaian languages, the position of the rich, original and unique languages of Ghanaian pride are not defined and the English language continues to enjoy the privileged position as the only official language. It also receives endorsement in the school curricular as the language of instruction from pre-school to the University level.

On the contrary, broadcasting and media related issues though introduced into the Gold Coast in the English language by the British, is now dominated by indigenous Ghanaian languages. This inconsistency has been attributed to the lack of an overarching National Language Policy which will spell out a language-use path of all language issues in Ghana. The negative impact of the absence of a National Language Policy document has been felt, especially in education at the lower primary level.

Efforts at developing indigenous languages have been unglamorous since they are not used for official government business and have also been left at the mercy of successive political governments. In promoting the national identity of Ghanaians, there is a need to channel resources and efforts in developing comprehensive vocabularies for indigenous Ghanaian languages so that they could be used without falling on ex-colonial languages as substitutes in certain situations. This paper has argued that, even before independence, the eleven languages that were sponsored for development are still the same being developed today. As a matter of urgency, efforts should be channelled in developing indigenous languages, especially minority and endangered languages to avoid sending them into extinction. It has also been argued that the time is ripe to accord some indigenous languages the national language status and ultimately be knitted into the official languages to draw up a National Language Policy (law) which will give a language direction for use in education, the media and all other spheres of national and international affairs.

\section{References}

Aboagye Da-Costa, C. (2018). Institutional assessment of the implementation of the National Media Commission's Guidelines for Local Language Broadcasting in local language news in Ghana: A case study of Hello FM. Masters' dissertation. University of South Africa, Pretoria.

Adedeji, A. O. (2015). Analysis of the use of English and indigenous languages by the press in selected African countries. Arabian Journal of Business and Management Review (OMAN Chapter),4(8), 35-45.

Alhassan, A. (2005). Market valorization in broadcasting policy in Ghana: abandoning the quest for media democratization. Media Culture \& Society, 27(2), 211-228.

Ansu-Kyeremeh, K. (2002). One nation, many tongues: language of FM broadcasting and the myth of a national culture, paper prepared for the community communication section of the 23rd General Assembly and Scientific Conference of the International Association of Media and Communication Research (IAMCR), Institut de Teatre, Tarcelona, Spain, 21-26 July 2002. [Online] Available: http://www.portalcomunicacion.com/bcn2002/n_eng/programme/prog_ind/papers/a/pdf/d_a013_ansu.pdf

Bamgbose, A. (2007). Multilingualism and exclusion: Policy, practice, and prospects. In M. Meeuwis, P. Cuvelier \& T. Du Plessis (Eds.), Multilingualism and exclusion (pp.1-11). Pretoria, Van Schaik.

Blankson, I. B. (2005). Negotiating the use of native languages in emerging pluralistic and independent broadcast systems in Africa. African Media Review, 13(1), 1-22.

Boadi, L. A. (1971). Education and the role of English in Ghana. In J. Spencer (Ed.), The English Language in West Africa (pp. 49 - 65). London: Longman Group.

Brand, G. (2011). African philosophy and the politics of language in Africa. Language Matters: Studies in the Languages in Africa, 42(2), 173-189.

Crystal, D. (2003). English as a global language.(2 ${ }^{\text {nd }}$ ed.). Edinburgh: UK, Cambridge University Press.

Dakubu, M. -E. K. (1973). Ga-English Dictionary. Legon: Institute of African Studies.

Dua, H. R. (1993). The national language and the ex-colonial language as rivals: the case of India. International Political Science Review, 14(3), 293-308.

Dzameshie, A. K. (1988). Language policy and the common language controversy in Ghana. Research Review MS, 4(2), 16-27. [Online] Available:

http://digital.lib.msu.edu/projects/africanjournals/

Fishman, J. A. (1994). Critiques of language planning: a minority languages perspectives. Journal of Multilingual and Multicultural Development, 15, 91-99. 
Flamenbaum, R. (2014). The pragmatics of codeswitching on Ghanaian talk radio. International Journal of Bilingualism, 18(4), 346-362.

Ghana. 2016. Local Governance Act. Accra, Government Printer.

Ghana Statistical Service. (2012). 2010 Population and housing census: summary report of final results. Accra: Sakoa.

Ghana. (1992). Constitution of the Republic of Ghana. Accra: Government Printer.

Gough, D. (1999). African languages: Discourse, concepts, education and other challenges. In K. K. Prah (Ed.), Knowledge in black and white: the impact of apartheid on the production and reproduction of knowledge (pp. 169-179). Cape Town: Centre for Advanced Studies of African Society (CASAS).

Grimes, B. (1984). Languages of the World. Ethnologue. Dallas: Wycliffe Bible Translators.

Heath, CW. 2001. Regional radio: A response by the Ghana Broadcasting Corporation to decentralization and competition. Canadian Journal of Communication, 26,89-106.

Iseke-Barnes, J. M. (2004). Politics and power of languages: indigenous resistance to colonising experiences of language dominance. Journal of Thought, 39(1), 45-81.

Ministry of Information, Ghana. (2014). Broadcasting Act. Accra: Government Printer.

Moyo, T. (2002). Mother tongues versus an ex-colonial language as media of instruction and the promotion of multilingualism: the South African experience. South African Journal of African Languages, 22(2), 149-160.

Mpofu, P.\& Mutasa, D. E. (2014). Language policy, linguistic hegemony and exclusion in the Zimbabwean print and broadcasting media. South African Journal of African Languages, 34(2), 225-233.

National Commission on Culture. [N.d.] The Bureau of Ghana Languages. [Online] Available: http://www.ghanaculture.gov.gh/index1.php?linkid=331\&page=2\&sectionid=602

National Media Commission. (2009). Guidelines for local language broadcasting. Accra: Government Printer.

National Media Commission. (2000). National Media Policy. Accra: Sakoa.

National Media Commission (2000) Broadcasting Standards. Accra.

Nyavor, G. M. K. (2010). Impact of Akan radio news presentation on the audience of Adom FM. Bachelor's dissertation. Accra. Ghana Institute of Journalism. [Online] Available:

https:www.scribd.com/doc/46413404.

Obeng, S. G. (1997). An analysis of the linguistic situation in Ghana. African Languages and Culture, 10(1), 63-81.

Opare-Henaku, J. (2016). An exploratory study of news room routines of local and English language radio stations: the case of Adom FM and Joy FM. MPhil dissertation. Accra: University of Ghana.

Opoku-Amankwa, K. (2009). English-only language-in-education policy in multilingual classrooms in Ghana. Language, Culture and Curriculum, 22(2), 121-135.

Owu-Ewie, C. (2006). The language policy of education in Ghana: a critical look at the English-only Language Policy of Education, selected proceedings of the $35^{\text {th }}$ Annual Conference on African linguistics, edited by J. Mugane. Somerville, MA, Cascadilla Proceedings Project: 76-85.

Parliament of Ghana. (2000). Standing Orders. Government Printer.

Peacefmonline.com. (2017). Hairdresser-Turned MP Ama Sey Makes First Speech On The Floor Of Parliament, $\left(20^{\text {th }}\right.$ December 2017)[Online] Available: http://www.peacefmonline.com/pages/politics/politics/201712/339149.php

Roy-Campbell, Z. M. (2006). The state of African languages and the global language politics: empowering African languages in the era of globalization. In O. F. Arasanyin, M. A. Pemberton and M. A. Sommerville (Eds.), Selection proceedings of the 36th Annual Conference on African Linguistics (pp. 1-13). Cascadilla Proceedings Project. [Online] Available

https://www.researchgate.net/publication/237526991_The_State_of_African_Languages_and_the_Global_Language_P olitics_Empowering_African_Languages_in_the_Era_of_Globalization

Salawu, A. (2010). A network of tongues: African languages, multilingualism and global communication. South African Journal of African Languages, 30(1), 66-71.

School of Communication Studies. (1993). Promotion of Privatization of Radio and Television Broadcasting in Ghana. Report of a national conference held in GIMPA, Legon: University of Ghana, March 1-3.

Spencer, J. (1971). West Africa and the English language. In J. Spencer (Ed.), The English Language in West Africa (pp. 1 - 34). London: Longman Group.

Spitulnik, D. (1998). Mediating unity and diversity: the production of language ideologies in Zambian broadcasting. In B. B. Schieffelin, K. A. Woolard \& P. V. Kroskrity (Eds.), Language ideologies: practice and theory (pp. 167188). NY: Oxford University Press. 